\title{
Research Paper: A Simulation Study With Electron- ic Dosimeter to Estimate Patient and Personnel Dose in Orthopedic Surgery
}

\author{
Akintayo Omojola $^{1^{*}}$ (D), Michael Akpochafor ${ }^{2}$ (D), Samuel Adeneye ${ }^{1}$
}

1. Radiology Department, Federal Medical Centre Asaba, Asaba, Nigeria

Citation Omojola A, Akpochafor M, Adeneye S. A Simulation Study With Electronic Dosimeter to Estimate Patient and Personnel Dose in Orthopedic Surgery. Journal of Research in Orthopedic Science. 2020; 7(2):61-66. http://dx.doi.org/10.32598/ JROSJ.7.2.667.1

http://dx.doi.org/10.32598/JROSJ.7.2.667.1

Keywords:

Simulation, Orthopedic, Radiation dose, Exposure, Personnel, Protective device, Entrance surface dose

\begin{abstract}
A B S T R A C T
Background: The use of mini C-arm is required in many orthopedic surgeries as an imageguided tool. Studies have shown an unnecessarily high dose to patients if exposures are not properly optimized. Also, scatter radiation to personnel may increase the risk of cancer if an appropriate protective device is not used.

Objectives: This study aims to determine the patient's dose and scatter radiation to the surgeon, anesthetist, and scrub nurse. Also, a comparison will be made with other studies on this topic.

Methods: A phantom was designed to simulate a patient on the operating table to produce scatter radiation. In the same vein, a mobile mini C-arm unit was positioned with the $\mathrm{x}$-ray tube beneath the head and the image receptor above the operating table. Measurements were made with a measuring tape from the central axis to the position of the surgeon, anesthetist, and scrub nurse. The Entrance Surface Dose (ESD) was determined by placing the electronic dosimeter at the surface of the phantom to estimate the patient dose. Similarly, each personnel dose/dose rate from the central axis was determined using a similar detector.
\end{abstract}

Results: The total average time for most orthopedic surgeries in the studied facility was 3.3 minutes. The estimated ESD to the patient was $25.03 \mu \mathrm{Sv}$ and the scatter radiation per patient reaching the simulated anesthetist, scrub nurse, and surgeon was, 3.75, 3.59, and $7.72 \mu \mathrm{Sv}$, respectively. The estimated dose values per year to anesthetist, scrub nurse, and surgeon were $390,373.36$, and $802 \mu \mathrm{Sv}$, respectively.

Conclusion: The personnel recommended limit dose rate was $<20000 \mu \mathrm{Sv} / \mathrm{y}$. The technical factor used and total exposure time from this study could have affected the radiation dose. This study showed that personnel was safe even without the use of lead apron. Nevertheless, the use of an appropriate protective device should be encouraged to ensure safety.

\footnotetext{
* Corresponding Author:

Akintayo Omojola, MSc.

Address: Radiology Department, Federal Medical Centre Asaba, Asaba, Nigeria.

Phone: +234 (808) 0545782

E-mail: akintayoomojola@gmail.com
} 


\section{Introduction}

rthopedic reconstructive or replacement surgeries have evolved and improved over the years with the advent of sophisticated imaging modalities like the mini C-arms with real-time imaging (Figure 1). With this recent development, many surgeries could be operated with greater ease, less time, and fewer patient complications. The outcomes are enhancing the technical proficiency of the surgeon with good results and better management of their patients [14]. At present, over $4000 \mathrm{x}$-ray units are used in Nigeria. Also, there is a hand full of orthopedic units in federal and state teaching hospitals, as well as private centers across the country where either a large or mini C-arm is used [5]. Besides, the number of medical specialists in other areas of medicine using fluoroscopy is immerging. However, studies indicate poor knowledge about exposure to radiation, its detrimental effect, and associated long-term risk, using C-arm fluoroscopy [6-8].

Generally, the primary beam from the tube head of the $\mathrm{x}$-ray unit reaches the patient directly, with higher intensity compared with the scattered radiation reaching the personnel. For most orthopedic surgeries, the chances of deterministic effects of radiation are low compared with high dose procedures like cardiac studies. A lot of investigations on the impact of radiation to orthopedic surgeons and support staff using the $\mathrm{C}$-arm have revealed that radiation doses incurred are far lower than the International Commission on Radiological Protection (ICRP) allowed limits.

Reported doses during various orthopedic procedures are usually below international standards, either as dose equivalent (which is a measure of biological damage that is calculated by multiplying absorbed radiation dose by a quality factor for the type of radiation involved) and effective dose (which represent the stochastic health effects of a low level of ionizing radiation on the human body, which represents the probability of radiation-induced cancer and genetic damage). Orthopedic surgeons receive radiation arising from primary (direct) and scatter radiation. The hands are most likely exposed directly to ionizing radiation during fluoroscopy screening [9-11]. Other organs with high radiosensitivity that are exposed to scatter radiation are the eye lens, thyroid, and gonads [12].

\section{Methods}

This retrospective study was carried for one month using the main hall of the hospital where the C-arm was located. The purpose is to enhance the technical proficiency of the orthopedic surgeons during their operations with a real-time imaging system. Personnel recruited for this study involved orthopedic surgeons, scrub nurses, and a medical physicist for dose measurements. A Philips BV Endura R2.3 single-phase and mobile fluoroscopic unit was used for this study. A phantom was locally designed to mimic the patient's position on the operating table as demonstrated in Figure 2. Various positions are assumed by personnel to estimate radiation dose by positioning the detector at various points. The points were assumed to be where the patients lie and personnel stand.

The Source To Patient Distance (SPD) was $0.5 \mathrm{~m}$, central-axis to anesthetist (CA) was $0.75 \mathrm{~m}$, central-axis to scrub nurse (CS n) was $0.87 \mathrm{~m}$ and central-axis to the surgeon (CS g) was $0.5 \mathrm{~m}$. Similarly, the beam-on time was assumed to be the actual time exposure. An inspector USB survey meter and an NT6200 Electronic Dosimeter were used for radiation measurements. The inspector is a health and safety instrument to detect low levels of radiation. It is designed to measure alpha $(\alpha)$ and beta particles $(\beta)$, gamma rays $(\gamma)$, and $x$-ray radiation (ionizing radiation only). It can work in milliroentgen per hour $(\mathrm{mR} / \mathrm{h})$ and count per minute (cpm) or SI unit of microsievert per hour $(\mu \mathrm{Sv} / \mathrm{h})$ and count per seconds (cps). Also, the technical parameters for the NT6200 Electronic Dosimeter can measure $\mathrm{x}$-ray, $\gamma$, and $\beta$ particles. The equivalent dose rate is calibrated to work from $0.01 \mu \mathrm{Sv} / \mathrm{h}$ to 100 $\mathrm{mSv} / \mathrm{h}$. Similarly, the radiation equivalent dose is 0.01 $\mu \mathrm{Sv}$ to $9999 \mathrm{~Sv}$. The energy ranged from $40 \mathrm{KeV}$ to 3.0 $\mathrm{MeV}$. Since $\mathrm{X}$-ray quality factor $=1$, then microsievert and microGrays units can be used interchangeably. The average technical factor used was $43 \mathrm{kVp}$ and $4 \mathrm{mAs}$.

\section{Results}

The maximum and minimum measured mean dose rates to the patient were $451.2 \mu \mathrm{Sv} / \mathrm{h}$ and $272.4 \mu \mathrm{Sv} / \mathrm{h}$ at 3.33 and 0.67 minutes exposure time, respectively. The mean scatter dose to the patient was estimated at 25.03 $\mu \mathrm{Sv} /$ case and $3.04 \mu \mathrm{Sv} /$ case, respectively (Table 1). Similarly, the maximum and minimum measured scatter mean dose rates to the anesthetist was $67.6 \mu \mathrm{Sv} / \mathrm{h}$ and $35.6 \mu \mathrm{Sv} / \mathrm{h}$ at 3.33 and 0.67 minutes exposure time, respectively. The mean scatter dose reaching the anesthetist without protective apron was estimated at $3.75 \mu \mathrm{Sv} /$ case and $0.4 \mu \mathrm{Sv} /$ case, respectively (Table 2 ).

In the same vein, the total maximum and minimum measured scatter mean dose rates to the scrub nurse was 64.8 $\mu \mathrm{Sv} / \mathrm{h}$ and $26.4 \mu \mathrm{Sv} / \mathrm{h}$ at 3.33 and 0.67 minutes exposure time, respectively. The mean scatter dose reaching the 
Table 1. Estimated dose to patient

\begin{tabular}{|c|c|c|c|}
\hline $\mathrm{SPD}(\mathrm{m})$ & Total Time (Minutes) & Measured Dose Rate $(\mu \mathrm{Sv} / \mathrm{hr})$ & Dose/Case ( $\mu \mathrm{Sv}$ ) \\
\hline 0.5 & 3.33 & 451.2 & 25.03 \\
\hline 0.5 & 0.67 & 272.4 & 3.04 \\
\hline
\end{tabular}

Table 2. Estimated dose to Anesthetist

\begin{tabular}{cccc}
\hline CA $(\mathrm{m})$ & Total Time (Minutes) & Measured Dose Rate $(\mu \mathrm{Sv} / \mathrm{hr})$ & Dose/Case $(\mu \mathrm{Sv})$ \\
\hline 0.75 & 3.33 & 67.6 & 3.75 \\
0.75 & 0.67 & 35.6 & 0.4 \\
\hline CA $=$ Central-axis to Anesthetist & & Orthopedic Science
\end{tabular}

scrub nurse without a protective apron was estimated at $3.59 \mu \mathrm{Sv} /$ case and $0.29 \mu \mathrm{Sv} /$ case, respectively (Table 3).

The maximum and minimum total measured scatter mean dose rates to the surgeon was $139.2 \mu \mathrm{Sv} / \mathrm{h}$ and $121.88 \mu \mathrm{Sv} / \mathrm{h}$ at 3.33 and 0.67 minutes exposure time, respectively. The mean scatter dose reaching the surgeon was estimated at $7.72 \mu \mathrm{Sv} /$ case and $1.33 \mu \mathrm{Sv} /$ case (without protective apron), respectively (Table 4).

The average dose impacted a total of 104 patients per year for the average maximum time of 3.33 minutes was estimated as $2603 \mu \mathrm{Sv} / \mathrm{y}$. The estimated average dose values to the surgeon, anesthetist, and scrub nurse per year were 802,390 , and $373.36 \mu \mathrm{Sv} / \mathrm{y}$, respectively.

\section{Discussion}

Orthopedic interventional procedures result in unavoidable radiation exposure to patients and personnel due to fluoroscopy exposure. The use of Electronic Dosimeter (ED) has become more popular because of the display of dose in real-time compared with Thermoluminescent Dosimeters (TLDs), which involves the use of a thermal stimulator be-

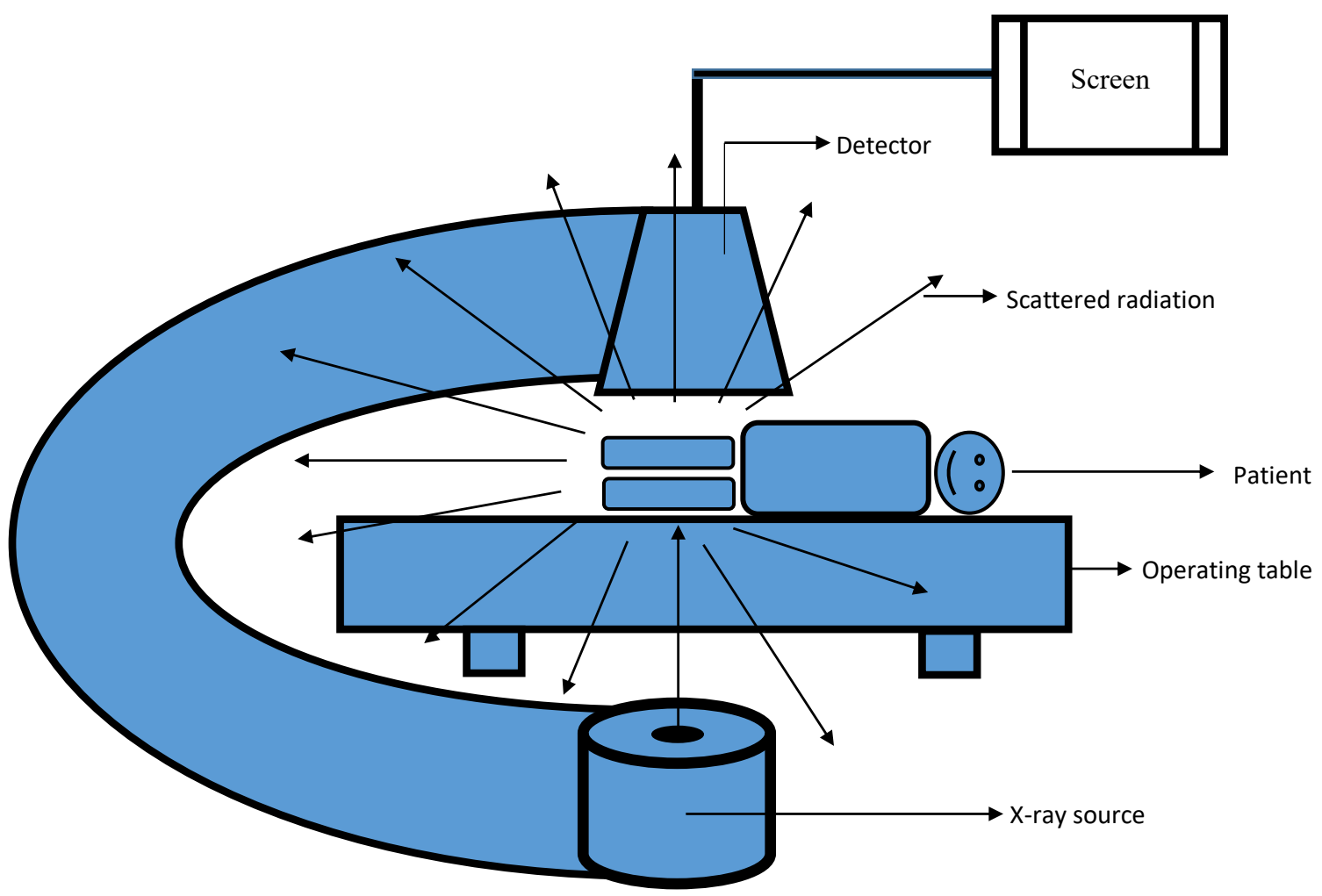

Figure 1. Schematic diagram of a C-arm, patient and radiation scattering effect 


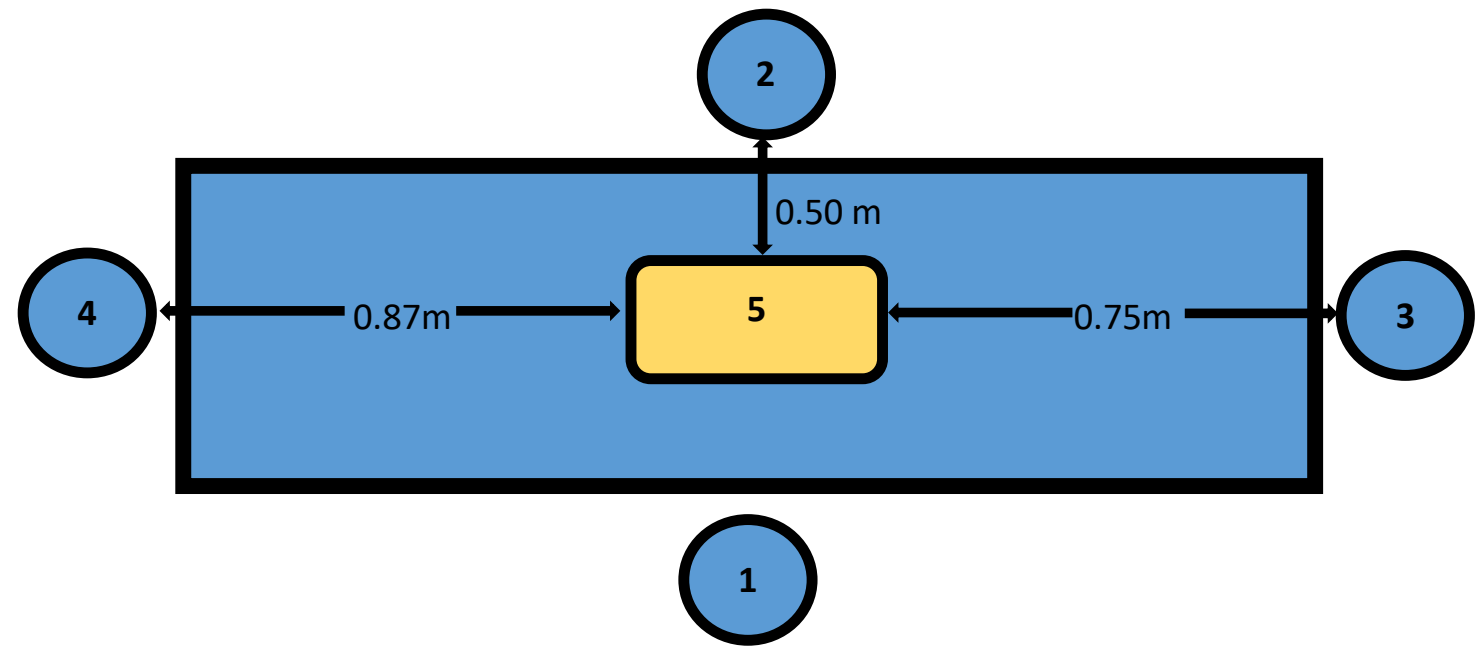

1. Mini C-arm; 2. Surgeon; 3. Anesthetist; 4. Scrub nurse; 5. Phantom

Figure 2. Positions of personnel in the orthopedic suit

Table 3. Estimated dose to Scrub nurse

\begin{tabular}{cccc}
\hline $\operatorname{CSn}(\mathrm{m})$ & Total Time (Minutes) & Measured Dose Rate $(\mu \mathrm{Sv} / \mathrm{hr})$ & Dose/Case $(\mu \mathrm{Sv})$ \\
\hline 0.87 & 3.33 & 64.8 & 3.59 \\
0.87 & 0.67 & 26.4 & 0.29 \\
\hline CSn $=$ Central-axis to Scrub nurse & &
\end{tabular}

Orthopedic Science

Table 4. Estimated dose to surgeon

\begin{tabular}{cccc}
\hline $\operatorname{CSg}(\mathrm{m})$ & Total Time (Minutes) & Measured Dose Rate $(\mu \mathrm{Sv} / \mathrm{hr})$ & Dose/Case $(\mu \mathrm{Sv})$ \\
\hline 0.5 & 3.33 & 139.2 & 7.72 \\
0.5 & 0.67 & 121.88 & 1.33 \\
\hline CSg $=$ Central-axis to Surgeon & & Orthopedic Science
\end{tabular}

fore dose can be determined. However, the latter still stands out as a "gold standard" for personal dosimetry $[13,15]$.

There were variations in personnel positions (surgeon, anesthetist, and scrub nurse) from the central-axis of the mini C-arm unit $(0.5,0.75$, and $0.87 \mathrm{~m})$. Mehlman et al., who used a fluoroscopy unit for personnel dose simulation, reported that the surgeon, anesthetist, and scrub nurse were at a distance of $0.305,1.524$, and $0.914 \mathrm{~m}$ away from the central axis. The anesthetist position was twice far than what was in our study. Also, results from Mehlman et al. study indicated that unprotected individuals working 36 inches $(0.914 \mathrm{~m})$ or far away from the beam axis would receive a much lower dose, which is in agreement with the inverse square law. The above result was in line with our study where the anesthetist and scrub nurse received 1.13 $\mu \mathrm{Sv} / \mathrm{min}$ and $1.08 \mu \mathrm{Sv} / \mathrm{min}$, respectively without protection [15]. Likewise, there was a slight difference in the distance from the central axis where the surgeon stands in this study $(0.7 \mathrm{~m})$ against the distance reported by Tasbas et al. study $(0.9 \mathrm{~m})$.

Radiation reading from an anesthetic position from an orthopedic surgery at a distance of $1.5 \mathrm{~m}$ was zero [16]. Simulated radiation dose to anesthesiologist at $0.9 \mathrm{~m}$ from the source of the $\mathrm{C}$-arm from this study was approximately $4 \mu \mathrm{Sv} /$ case. Alonso et al. used an electronic dosimeter and reported that for a Dynamic Hip Screw (DHS) fixation of the femur, the estimated dose to an anesthetist, standing 2 $\mathrm{m}$ away from the $\mathrm{C}$-arm, was a maximum value of $1 \mu \mathrm{Sv}$ for two measurements. There was no evidence of radiation dose for most measurements made [17].

The position of the anesthetist in our study was $0.9 \mathrm{~m}$ away, which recorded a maximum dose of $3.75 \mu \mathrm{Sv}$. Also according to the perspex phantom experiment by Lo et al., the radiation dose in orthopedic surgeries to the surgeon and operating personnel for a distance of $1 \mathrm{~m}$ to the head, 
waist, and feet ranged from 50 to $100 \mu \mathrm{Sv} / \mathrm{h}$. In our study, the distance was $0.7-1 \mathrm{~m}$ from the surgeon and operating theatre personnel, with a range of $64.8-139 \mu \mathrm{Sv} / \mathrm{h}$ [18].

An accumulated dose of as little as $65 \mu \mathrm{Sv}$, which is frequently exceeded during most orthopedic procedures, over multiple exposures can statistically increase the incidence of thyroid cancer after many years [19]. It can be seen that an average of 17.3 cases would exceed the above value $(65 \mu \mathrm{Sv})$ over 2 months for a surgeon. Mesbahi et al., who investigated radiation dose to surgeon and staff, reported that entrance skin exposure to the surgeon's hand, eye, and thyroid varied from 0.85-8036 $\mu \mathrm{Sv} / \mathrm{min}$. This study was seen to be within this range based on our simulated value of $2.32 \mu \mathrm{Sv} / \mathrm{min}$ [20].

The fluoroscopy times in commonly performed fracture of the femur in a study by Tsalafoutas et al. were 3.2, 1.5, and $6.3 \mathrm{~min}$ based on different types of surgery [12]. The maximum mean time from our simulated study was about $3.3 \mathrm{~min}$, which was close to one of the quoted times above. Whittaker et al. study shows an average dose range of 0.1 $2.4 \mathrm{~min}$ with intramedullary nailing having the highest time. The most seen orthopedic cases in the studied facility were Open Reduction Internal Fixation (ORIF) with an average time of $0.67 \mathrm{~min}$. Based on Whittaker et al. study results, the average screening time for post ORIF was $0.16 \mathrm{~min}$ [21]. The patient dose in this study ranged from 3.04 to $25.03 \mu \mathrm{Sv}$, with its maximum value close to a surgically-treated femoral fracture studied by Perisinakis et al. whose dose ranged from 11.6 to $21.7 \mu \mathrm{Sv}$ [22].

In most cases, discrepancies in effective doses are largely due to exposure time variation, size of the patient, and the point source of measurement. In another study, Suhm et al. reported an effective dose of $100 \mu \mathrm{Sv}$ to patients for lower extremity fractures, which was four times higher than our value $(25.03 \mu \mathrm{Sv})$ [23].

The estimated scatter radiation for a few commonly performed orthopedic surgeries like intramedullary nailing of pertrochanteric fracture ranged from $0.012-0.103 \mathrm{mSv} /$ $\min$ [12]. The above results were higher than our study which was $0.00218 \mathrm{mSv} / \mathrm{min}$ on average. Surgeon dose (7.72 $\mu \mathrm{Sv} /$ case) based on our study was lower compared with Osman et al. [24] who investigated surgeon dose to the thyroid in orthopedic surgeries. His study looked at two different kinds of orthopedic surgeries, which resulted in a mean thyroid dose of $71.6 \mu \mathrm{Gy} /$ case and $57.6 \mu \mathrm{Gy} /$ case. The relative dose difference was $161 \%$ and $150 \%$, respectively. The mean estimated dose to personnel from this study was $5.02 \mu \mathrm{Sv}$; this value was close to a study carried out by Zweers et al., who investigated patient and staff dose. The estimated dose to staff per procedure was 28 and $4 \mu \mathrm{Sv}$ from two different hospitals using an electronic dosimeter [25]. Henderson et al. studied the radiation exposure of anesthetists. They concluded that at 1.5 $\mathrm{m}$ distance from the radiation source, the unprotected average equivalent dose readings were undetectable from prospective case series over two months [26].

Compensation for staff movement within the room during the procedure was not possible because the phantom was static. In this regard, the dose may be slightly affected. Second, the average exposure time was based on commonly performed orthopedic surgeries. Procedures with a much longer time were not investigated in this study.

\section{Conclusion}

An investigation was conducted to estimate patient and personnel radiation dose values from a mini $\mathrm{C}$-arm unit. The total exposure time was mostly dependent on the type of orthopedic surgery and the experience of the surgical team. Also, the exposure time and distance from the radiation source were directly proportional to the dose received by the personnel. Although radiation doses were generally small in magnitude, there must be strong regulation on the use of the protective device during these procedures. Studies have shown that with continual exposure to low ionizing radiation there might be a potential stochastic risk.

\section{Ethical Considerations}

\section{Compliance with ethical guidelines}

All ethical principles were considered in this article.

\section{Funding}

This research did not receive any specific grant from funding agencies in the public, commercial, or not-forprofit sectors.

\section{Authors' contributions}

All authors contributed in preparing this article.

\section{Conflict of interest}

The authors declared no conflict of interest. 


\section{Reference}

[1] Fleming ME, Watson JT, Gaines RJ, O'Toole RV. Evolution of orthopaedic reconstructive care. J Am Acad Orthop Surg. 2012; 20(Suppl. 1):S74-9. [DOI:10.5435/JAAOS-20-08-S74] [PMID]

[2] Salsberg ES, Grover A, Simon MA, Frick SL, Kuremsky MA, Goodman DC. An AOA critical issue. Future physician workforce requirements: Implications for orthopaedic surgery education. J Bone Joint Surg Am. 2008; 90:1143-59. [DOI:10.2106/JBJS.G.01305] [PMID] [PMCID]

[3] Hoppe DJ, Bhandari M. Evidence-based orthopaedics: A brief history. Indian J Orthop. 2008; 42:104-10. [DOI:10.4103/0019-5413.40244] [PMID] [PMCID]

[4] Ojodu I, Ogunsemoyin A, Hopp S, Pohlemann T, Ige O, Oluwaseun A. C-arm fluoroscopy in orthopaedic surgical practice. Eur J Orthop Surg Traumatol. 2018; 28(8):1563-8. [DOI:10.1007/s00590-018-2234-7] [PMID]

[5] Akpochafor MO, Omojola AD, Adeneye SO, Aweda MA, Ajayi HB. Determination of reference dose level among selected X-ray centres in Lagos, South-West Nigeria. J Clin Sci. 2016; 13:167-72. [DOI:10.4103/2468-6859.192275]

[6] Van Papendorp LWA, Suleman FE, Hanekom H. The knowledge, awareness and practices of radiation safety amongst orthopaedic surgeons. S Afr J Rad. 2020; 24(1):a1806. [DOI:10.4102/sajr.v24i1.1806] [PMID] [PMCID]

[7] Downey C, McCarrick C, Fenelon C, Murphy EP, O'Daly BJ, Leonard $\mathrm{M}$. A novel approach using 3-D printing in the Irish National Centre for pelvic and acetabular surgery. Ir J Med Sci. 2020; 189(1):219-28. [DOI:10.1007/s11845-019-02055-y] [PMID]

[8] Tunçer N, Kuyucu E, Sayar Ş, Polat G, Erdil İ, Tuncay İ. Orthopedic surgeons' knowledge regarding risk of radiation exposition: A survey analysis. SICOT J. 2017; 3:29. [DOI:10.1051/sicotj/2017008] [PMID] [PMCID]

[9] Giordano BD, Baumhauer JF, Morgan TL, Rechtine GR. Cervical spine imaging using standard C-arm fluoroscopy. Patient and surgeon exposure to ionizing radiation. Spine. 2008, 33(18):1970-6. [DOI:10.1097/BRS.0b013e31817e69b7] [PMID]

[10] Giordano BD, Baumhauer JF, Morgan TL, Rechtine GR. Cervical spine imaging using mini C-arm fluoroscopy: $\mathrm{Pa}$ tient and surgeon exposure to direct and scatter radiation. Journal of Spinal Disorders and Techniques. 2009a 22(6):399403. [DOI:10.1097/BSD.0b013e3181847559] [PMID]

[11] Singer G. Occupational radiation exposure to the surgeon. J Am Acad Orthop Surg. 2005; 13: 69-76. [DOI:10.5435/00124635-200501000-00009] [PMID]

[12] Tsalafoutas IA, Tsapaki V, Kaliakmanis A, Pneumaticos S, Tsoronis F, Koulentianos ED, et al. Estimation of radiation doses to patients and surgeons from various fluoroscopically guided orthopaedic surgeries. Radiat Prot Dosim. 2008; 128(1):112-9. [DOI:10.1093/rpd/ncm234] [PMID]

[13] Sung S, Lim S, Min K, Jung Y, Cho Y, Kim M, et al. Radiation exposure during C-arm-guided (fluoroscopy) small animal orthopaedic surgery. Veterinarni Medicina. 2018; 63(11):527-31 [DOI:10.17221/15/2018-VETMED]

[14] Van Rappard JRM, De Jong t, Hummel WA, Ritt MJPE, Mouës CM. Radiation exposure to surgeon and assistant during flat panel mini C-Arm fluoroscopy in hand and wrist surgical procedures. J Hand Surg Am. 2019; 44(1):68.e1-e5. [DOI:10.1016/j.jhsa.2018.05.010] [PMID]

[15] Mehlman CT, DiPasquale TG. Radiation exposure to the orthopaedic surgical team during fluoroscopy: "How far away is far enough?". J Orthop Trauma. 1997; 11: 392-8. [DOI:10.1097/00005131-199708000-00002] [PMID]

[16] Tasbas BA, Yagmurlu MF, Bayrakci K, Ucaner A, Heybeli M. Which one is at risk in intraoperative fluoroscopy? Assistant surgeon or orthopaedic surgeon? Arch Orthop Traum Su. 2003; 123:242-4. [DOI:10.1007/s00402-003-0516-x] [PMID]

[17] Alonso JA, Shaw DL, Maxwell A, McGill GP, Hart GC. Scattered radiation during fixation of hip fractures. Is distance alone enough protection? J Bone Jt Surg. 2001; 83:815-8. [DOI:10.1302/0301-620X.83B6.0830815]

[18] Lo NN, Goh PS, Khong KS. Radiation dosage from use of the image intensifier in orthopaedic surgery. Singapore Med J. 1996; 37(1):69-71. [PMID]

[19] Troisi K. Radiation exposure to orthopedic registrars in the Pietermaritzburg Metropolitan Complex. SA Orthop J. 2016; 15:38-42. [DOI:10.17159/2309-8309/2016/v15n2a6]

[20] Mesbahi A, Rouhani A. A study on the radiation dose of the orthopaedic surgeon and staff from a mini C-arm fluoroscopy unit. Radiat Prot Dosimetry. 2008; 132:98-101. [DOI:10.1093/rpd/ncn227] [PMID]

[21] Whittaker M, Faroug R, Jenkins J. Thyroid Shield Wear in Orthopaedic Surgery: An Audit of Practice. J Radiol Res Prac. 2014(2014)541546:1-8. [DOI:10.5171/2014.541546]

[22] Perisinakis K, Damilakis J, Theocharopoulos N. Patient effective dose and radiogenic risks from fluoroscopically assisted surgical reconstruction of femoral fractures. Radiat Prot Dosimetr. 2004; 108:65-72. [DOI:10.1093/rpd/nch005] [PMID]

[23] Suhm N, Jacob A, Zuna AL, Roser HW, Regazzoni P, Messmer P. Radiation exposure of the patient by intraoperative imaging of intramedullary osteosynthesis. Radiologe. 2001; 41(1):91-4. [DOI:10.1007/s001170050932] [PMID]

[24] Osman H, Sulieman A, Sam AK. Orthopedist's thyroid radiation dose during surgery. JAMR. 2011; 1:55-60

[25] Zweer D, Geleijns J, Aarts NJM, Hardam LJ, Laméris JS, Schultz FW, et al. Patient and staff radiation dose in fluoroscopy-guided TIPS procedures and dose reduction, using dedicated fluoroscopy exposure settings. Br J Radiol. 1998; 71(846):672-6. [DOI:10.1259/bjr.71.846.9849393] [PMID]

[26] Henderson KH, Lu JK, Strauss KJ, Treves ST, Rockoff MA. Radiation exposure of anesthesiologists. J Clin Anesth. 1994; 6:37-41. [DOI:10.1016/0952-8180(94)90116-3] 